\title{
High Cervical Partial Posterior Cord Cleft in a Case of Klippel-Feil Syndrome
}

\author{
Anshul Arora ${ }^{1}$, Kunal Singh Ahluwalia², Puneet Mittal ${ }^{3}$, Dhaarna Sharma ${ }^{4}$ \\ 1,2, 3,4 Department of Radiology, M.M. Institute of Medical Sciences and Research, Mullana, Ambala, Haryana, India
}

\section{INTRODUCTION}

Posterior high cervical spinal cord cleft has been rarely reported in association with Klippel - Feil syndrome (KFS). Its presence may have prognostic value in long term neurological outcome.

If there is segmentation anomaly of two or more vertebrae during embryonic life mainly involving the cervical vertebrae, it can result in Klippel - Feil syndrome. It is a rare anomaly and is present with the incidence of $1: 42000$ births. ${ }^{1}$ During $2^{\text {nd }}$ to $8^{\text {th }}$ week of embryonic life, the segmentation of the mesodermal somites of the spine in the cervical region fails and leads to cervical spine synostosis which is also known as KFS. Although most commonly the KFS patients present with the symptoms of short length of the neck, hairline posteriorly is low and the mobility in the upper part of the spine is restricted.

It is also sometimes associated with other congenital anomalies like Sprengel's deformity, hemivertebra, basilar impression, cleft palate, and many more rare anomalies. ${ }^{2}$ Most commonly the patients having this syndrome show restriction of the motion in the neck region. ${ }^{3}$

\section{PRESENTATION OF CASE}

A 4-year-old male child, with non - consanguineous parents, presented with chief complaint of decreased range of neck motion. Birth history was normal. There was no history of fever or trauma. On examination, no neurological deficit was seen. On computerised tomography (CT), multilevel vertebral fusion was seen consistent with diagnosis of Klippel - Feil syndrome (Figure 1).

Magnetic resonance imaging (MRI) showed multilevel vertebral fusion. In addition, it showed high cervical posterior spinal cord cleft filled with cerebrospinal fluid (CSF) extending from medulla oblongatae to C4 level, however spinal cord showed normal signal intensity. No septum or intra - spinal mass lesion was seen.
Corresponding Author:

Dr. Anshul Arora,

Department of Radiology,

M.M. Institute of Medical Sciences and

Research, Mullana, Ambala,

Haryana, India.

E-mail: arora.ashu123@gmail.com

DOI: $10.14260 / j e m d s / 2021 / 355$

How to Cite This Article:

Arora A, Ahluwalia KS, Mittal P, et al. High cervical partial posterior cord cleft in a case of klippel - feil syndrome. J Evolution Med Dent Sci 2021;10(22):1723-1725, DOI: $10.14260 /$ jemds $/ 2021 / 355$

Submission 28-01-2021,

Peer Review 01-04-2021

Acceptance 08-04-2021,

Published 31-05-2021.

Copyright (c) 2021 Anshul Arora et al. This is an open access article distributed under Creative Commons Attribution License [Attribution 4.0 International (CC BY 4.0)] 

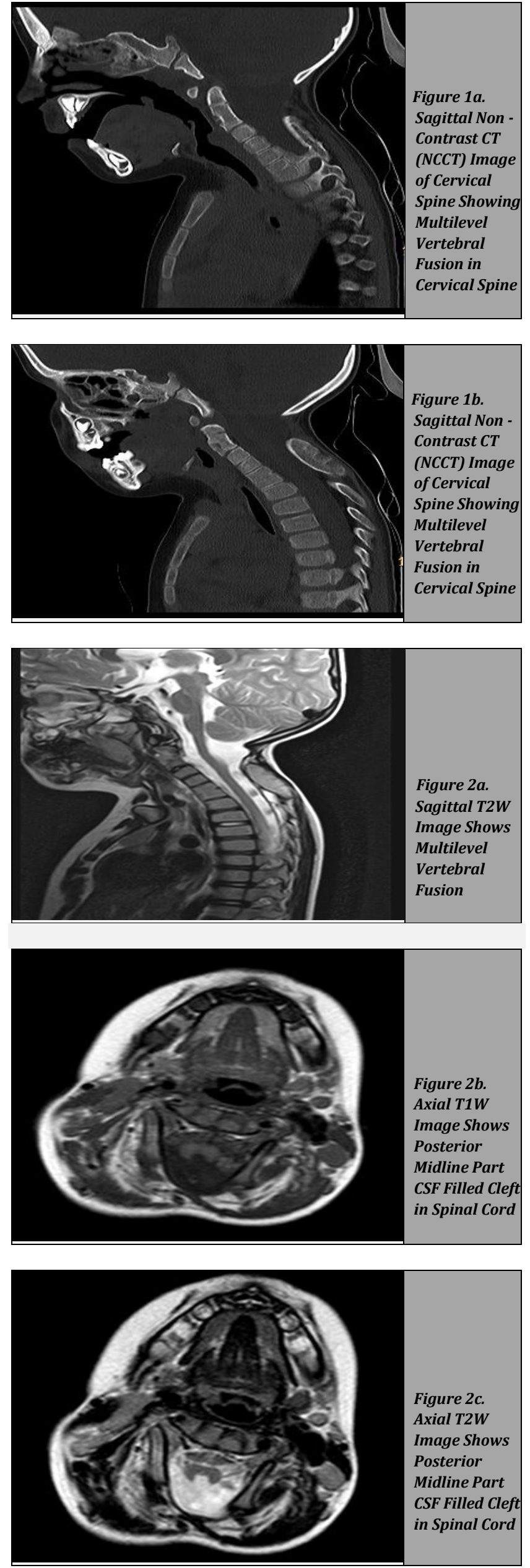

\section{DISCUSSION}

Klippel - Feil syndrome is a rare condition of unknown aetiology. It is a congenital vertebral segmentation anomaly characterized by multilevel vertebral fusion in cervical region (at two or more levels) which can also affect thoracic region. ${ }^{4}$ The short neck, low posterior hairline and reduced range of neck motion forms a classical triad which was originally described by Maurice

Klippel and André Feil but is only seen in less than half of the patients.5,6 It can be associated with a variety of other manifestations like Sprengel's shoulder, hearing problems and split cord malformations. ${ }^{7}$ Patients with Klippel - Feil syndrome are at increased risk of neurological deficit. This can be secondary to spinal instability and increased incidence of spondylosis changes due altered biomechanics due to multilevel vertebral fusion and increased stress at non - fused segments.

Another cause of neurological deficit is split cord malformations. ${ }^{6-8}$ Diastematomyelia is the most common split cord malformation which is usually seen in thoraco - lumbar region. It involves complete cord splitting which may or may not be associated with osseocartilaginous septum. Partial posterior spinal cord cleft, also known as partial diastematomyelia has been reported in association with Klippel - Feil syndrome.6,9 Its aetiology is not well described but it could be related to focal ischaemic injury without any subsequent repair.

Regardless of its aetiology, it may be an important prognostic factor as it is associated with long term neurological outcome. ${ }^{6}$ In our patient, there was no neurological deficit at presentation, however such patients with pre - existing spinal cord changes should be monitored closely and additional precautional measures should be instated to reduce incidence of spondylitic disease.6,7

Financial or other competing interests: None.

Disclosure forms provided by the authors are available with the full text of this article at jemds.com.

\section{REFERENCES}

[1] Thomsen MN, Schneider U, Weber M, et al. Scoliosis and congenital anomalies associated with Klippel-Feil syndrome types I-III. Spine (Phila Pa 1976) 1997;22(4):396401.

[2] Fernandes T, Costa C. Klippel-Feil syndrome with other associated anomalies in a medieval Portuguese skeleton (13th-15th centuries). J Anat 2007;211(5):681-5.

[3] Hensinger RN, Lang JE, MacEwen GD. Klippel-Feil syndrome: a constellation of associated anomalies. J Bone Joint 1974;56(6):1246-53.

[4] Karasick D, Schweitzer ME, Vaccaro AR. The traumatized cervical spine in Klippel-Feil syndrome: imaging features. AJR Am J Roentgenol 1998;170(1):85-8.

[5] Klippel M, Feil A. Un cas d'absence des vertèbres cervicales avec cage thoracique remontant jusqu'à la base du crâne. Nouvelle Iconographie de la Salpétrière 1912;25:223-50. 
[6] Vieira VLG, Bertholdo D. Klippel-Feil syndrome accompanied by partial cleft of the cervical spine: a notso-unusual combination? Radiol Bras 2019;52(1):65-6.

[7] Wessell A, DeRosa P, Cherrick A, et al. Cervical instability in Klippel-Feil syndrome: case report and review of the literature. Chin Neurosurg J 2015;1:6.
[8] David KM, Copp AJ, Stevens JM, et al. Split cervical spinal cord with Klippel-Feil syndrome: seven cases. Brain 1996;119(Pt 6):1859-72.

[9] Royal SA, Tubbs RS, D'Antonio MG, et al. Investigations into the association between cervicomedullary neuroschisis and mirror movements in patients with Klippel-Feil syndrome. AJNR Am J Neuroradiol 2002;23(4):724-9. 